\title{
TUMORES CONGENITOS DO SISTEMA NERVOSO: CORDOMAS
}

\author{
Walter C. Pereira * \\ MaURício A. Zelauy **
}

Os cordomas são bastante raros. Poppen e King ${ }^{16}$, entre 1.800 tumores operados, encontraram apenas 13 cordomas $(0,72 \%)$; Petit-Dutaillis e col. e Tönnis (citados por Zoltán e Fényes ${ }^{21}$ ) referem, respectivamente, 0,13 e $0,2 \%$ de cordomas em suas casuísticas de tumores comprometendo o sistema nervoso. Moya ${ }^{15}$ considera que o número relativamente elevado de cordomas registrados na literatura constitui prova da sua raridade, pois são publicados todos os casos observados em serviços especializados. Em sua grande maioria as publicações sôbre o assunto baseiam-se em observações isoladas ou em pequeno número de casos, sendo poucos os autores que registram casuisticas próprias numerosas ${ }^{4,9,16}$.

Forti e Venturini ${ }^{5}$, revendo a literatura em 1960, encontraram registram dos 548 cordomas, sendo 240 intracranianos, 81 vertebrais e 227 sacrococcígeos; entre os intracranianos incluíram 43 casos de ecordoses fisalíforas. Segundo outros 12, 14, 18, as ecordoses não devem ser consideradas como neoplasias verdadeiras e sim coristomas, isto é, malformações teciduais deslocadas de sua sede original. Êstes hemartomas não costumam dar sintomatologia, sendo encontramos em cêrca de $2 \%$ das necropsias na região do clivo de Blumembach ${ }^{17}$ e mais raramente nas regiões cervical e sacrococcígea ${ }^{15}$.

Origem e localização - Os cordomas originam-se dos resquícios da notocorda persistentes após a embriogênese, nos núcleos pulposos dos discos intervertebrais e em restos aberrantes heterotópicos sediados ao longo da primitiva localização da corda dorsal. Podem, portanto, situar-se em qualquer ponto da coluna vertebral ou na região da linha média da base do crânio, desde o buraco occipital até o plano esfenoidal. Alguns casos de cordomas primitivos têm sido descritos no osso maxilar, na mandíbula e na laringe; Moya ${ }^{15}$ não admite tais situações, pois não existem restos cordais com esta localização.

A maior parte dos cordomas origina-se em restos heterotópicos da notocorda situados nas regiōes sacrococcígea e esfeno-occipital. Os vertebrais, em geral originados dos núcleos pulposos dos discos intervertebrais, são

Trabalho da Clinica Neurológica (Prof. Adherbal Tolosa) e do Departamento de Anatomia Patológica (Prof. Constantino Mignone) da Faculdade de Medicina da Universidade de São Paulo: *Neurocirurgião; ** Assistente do Departamento de Anatomia Patológica. 
mais raros. Na revisão feita por Forti e Venturini ${ }^{5}$, cêrca de $85 \%$ dos cordomas distribuíam-se nas regiōes sacrococcígea e intracraniana, aproximadamente em igual proporção, e apenas $15 \%$ em outras partes da coluna vertebral.

Incidência - Embora classificados entre os tumores congênitos do sistema nervoso ${ }^{10,19}$, é rara a ocorrência de cordomas na infância; sendo excepcional o seu registro em recém-nascidos e fetos ${ }^{14,21}$. Os intracranianos incidem dos 20 aos 40 anos e os vertebrais e sacrococcígeos depois dos 50 anos, segundo a maioria dos autores. Mabrey ${ }^{11}$, em estudo sôbre 150 cordomas intracranianos, refere $13 \%$ antes dos 20 , e $25 \%$ antes dos 30 anos.

Os cordomas ocorrem mais freqüentemente no sexo masculino; segundo Godtfredsen ${ }^{7}$ incidem duas vêzes mais no homem que na mulher; Moya ${ }^{15}$ em 117 casos de cordomas intracranianos verificou a incidência de 60 a $40 \%$, respectivamente.

O papel dos traumatismos como fator desencadeante dos cordomas é discutido. Ribbert 17 conseguiu reproduzir experimentalmente estas neoplasias em cobaios, puncionando a borda anterior de discos intervertebrais. Estas experiências não foram confirmadas por vários autores, porém Congdon ${ }^{3}$, em 1952, introduzindo uma substância carcinogenética (20-metilcolantreno) após a punção de discos intervertebrais, verificou o crescimento de tumores histològicamente idênticos aos cordomas. Moya ${ }^{15}$ encontrou referências a traumatismos em 5,8\% de cordomas intracranianos, afirmando que - mecanismo traumático estaria mais freqüentemente relacionado com os vertebrais e sacrococcigeos.

Sintomatologia - O aparecimento tardio dos sintomas nestas neoplasias decorre, possivelmente, de seu crescimento muito lento, surgindo mais precocemente nos intracranianos em virtude da maior vulnerabilidade das estruturas desta região ${ }^{15}$. A sintomatologia evolui lentamente, iniciando, em geral, mais de um ano antes da internação ${ }^{9}$; os sintomas são os mesmos de outros tipos de neoplasias com a mesma localização. Os cordomas intracranianos, apesar de crescerem bilateralmente, o fazem de maneira assimétrica, determinando o aparecimento de sintomas predominantemente unilaterais. Kamrin e col. ${ }^{9}$ subdividem estas neoplasias em dois grupos:

Cordomas parasselares que afetam do $1^{\circ}$ ao $7^{\circ}$ nervos cranianos e apresentam a triade sintomática: cefaléia, alterações visuais e comprometimento dos nervos oculomotores. A lesão da hipófise é freqüente, acarretando perturbações endócrinas, principalmente referentes às funções genitais, ocorrendo impotência no homem e amenorréia na mulher em 10 a $20 \%$ dos $\operatorname{casos}^{9}$. Estes tumores podem crescer para o seio esfenoidal, invadindo ulteriormente a nasofaringe, surgindo sintomas de obstrucão das vias aéreas ${ }^{6}$. O exame fundoscópico revela edema das papilas ópticas e sinais de atrofia primária em igual número de casos.

Cordomas do clivo que afetam do $8^{\circ}$ ao $12^{\circ}$ nervos cranianos e, eventualmente, as primeiras raizes cervicais, com o aparecimento de dor na nuca; a sindrome do ângulo ponto-cerebelar é freqüentemente encontrada neste grupo ${ }^{16}$. 
Em ambos os grupos pode haver comprometimento de vias motoras e sensitivas, ocorrendo sintomas contralaterais aos nervos cranianos afetados. Mais raramente há bloqueio total do trânsito liquórico ao nível das cisternas basais ou do sistema ventricular, com sintomas intensos de hipertensão intracraniana.

A subdivisão dos cordomas intracranianos em parasselares e do clivo é esquemática, havendo tumores que ocupam simultâneamente as fossas média e posterior comprometendo todos os nervos cranianos, em geral, unilateralmente ${ }^{2}$. O diagnóstico diferencial deve ser feito com numerosas outras neoplasias: adenomas cromófobos da hipófise, craniofaringeomas, neurinomas do acústico, meningeomas, carcinomas nasofaríngeos, metástases de carcinomas e sarcomas, condromas, condrossarcomas, angiomas do glomo da jugular, mielomas 2, 9, 16, 21 .

Os cordomas vertebrais produzem sintomas de compressão radiculo-medular sem qualquer especificidade que permita diferença-los de outras neoplasias raqueanas. Podem crescer tanto em direção ventral como dorsal, podendo, neste último caso, tornarem-se palpáveis através do tegumento cutâneo. Os cordomas vertebrais com crescimento anterior determinam compressão de vísceras e vasos do pescoço, do tórax ou do abdome, de acôrdo com sua localização. O principal diagnóstico diferencial destas neoplasias é com os sarcomas e carcinomas metastáticos ${ }^{16}$.

Os cordomas sacrococcígeos comprometem as últimas raízes da cauda eqüina, provocando dores e desordens esfincterianas. Da mesma forma que os vertebrais podem expandir-se ventral ou dorsalmente, comprimindo estruturas da cavidade pélvica ou formando grandes massas palpáveis externamente ${ }^{14,20}$.

Aspectos radiológicos - Ao contrário do que acontece com o quadro clínico que é totalmente inespecífico, a radiografia simples fornece elementos que podem sugerir o diagnóstico de cordoma. Os principais dados fornecidos por êste exame são extensas zonas de destruição óssea e calcificações intratumorais. Para Poppen e King 16 a acentuada osteólise que os cordomas provocam é o principal elemento para o diagnóstico diferencial com outras neoplasias. Moya ${ }^{15}$, no entanto, não encontrou alterações radiológicas evidentes em $\mathbf{1 8 , 5} \%$ dos cordomas intracranianos. A maioria dos autores descreve lesōes osteodestrutivas, porém Poppen e King ${ }^{16}$ referem casos com neoformação e esclerose ósseas visíveis radiològicamente. Ventriculografias - Nos cordomas intracranianos o estudo contrastado dos ventrículos medianos fornece dados de grande valor diagnóstico; há deslocamento para trás e elevação do $3 .^{\circ}$ e $4 .^{\circ}$ ventrículos e do aqueduto cerebral $\mathrm{\epsilon m} 90 \%$ dos casos ${ }^{15}$; dilatação ventricular ocorre quando há bloqueio total ou subtotal do trânsito liquórico (20\% dos casos segundo Moya ${ }^{15}$ ). Pneumocisternografias - $\mathrm{O}$ estudo das cisternas basais é de grande interêsse, pois a neoplasia pode preenchê-las parcial ou totalmente, de acôrdo com sua localização e extensão. Arteriografias - A carotidoangiografia, nos cordomas suprasselares, mostra elevação do segmento $\mathrm{A}_{1}$ da artéria cerebral anterior e, às vêzes, deslocamentos anteriores e laterais do sifão carotídeo; 
quando a necplasia se expande para a fossa média ocorre elevação do grupo silviano; sinais de dilatação ventricular são encontrados quando há bloqueio total ou parcial do trânsito liquórico. Perimielografias - O exame contrastado do canal raqueano é útil para a localização exata da neoplasia, não fornecendo, em geral, elementos para seu diagnóstico específico ${ }^{16}$.

Provas laboratoriais - O exame do líquido cefalorraqueano não fornece dados específicos, ocorrendo elevações mais ou menos pronunciadas da pressão e da taxa protêica nos cordomas intracranianos e bloqueios parciais ou totais do canal raqueano nos vertebrais.

Anatomia patológica - Os cordomas sempre se apresentam sob forma globosa com limites bem evidentes e dimensões variáveis; os maiores atingem o volume de uma cabeça de adulto localizando-se na região sacrococcígea ${ }^{14}$; os intracranianos raramente ultrapassam $7 \mathrm{~cm}$ de diâmetro ${ }^{7}$. A superfície externa, lisa ou bocelada, é regularmente envolvida por uma cápsula fibrosa de espessura variável. A superfície de corte tem aspecto lobular, dado pela presença de numerosos septos fibrosos que, partindo da cápsula, dividem o tecido neoplásico em áreas arredondadas, ovóides ou alongadas, de tamanhos variados. O parênquima varia de aspecto, podendo apresentar-se como massas sólidas, consistentes, densas e opacas, de côr branco-acinzentada; outras vêzes sofre uma degeneração mucóide, tornando-se gelatinoso, transparente, de côr branca ou azulada e de consistência diminuida. As zonas centrais dos lóbulos podem apresentar focos de hemorragia antiga ou recente e áreas de necrose.

O aspecto macroscópico dos lóbulos neoplásicos desde o início pode fornecer informações úteis no sentido de esclarecer o grau de malignidade da neoplasia. De modo geral, pode-se estabelecer que o tumor será tanto mais benigno quanto mais extenso fôr o processo de degeneração mucóide; ao contrário, são mais malignos aquêles em que os lóbulos apresentam-se densos e opacos ${ }^{4}$.

Sob o ponto de vista histológico os cordomas podem ser típicos, quando reproduzem o aspecto do tecido cordal jovem e apresentam caráter epitelial, ou atípicos, com caráter sarcomatoso. Entre êstes dois extremos identificam-se formas mistas, nas quais são encontrados elementos epiteliais de mistura com sarcomatosos. O diagnóstico seguro será feito sỏmente quando o tumor se apresentar sob as formas típica ou mista.

O elemento característico desta neoplasia é a célula fisalífora que, enquanto jovem, apresenta forma arredondada ou poliédrica, com citoplasma abundante, homogêneo e eosinófilo; o núcleo é grande, central, redondo ou ovóide, contendo massas de cromatina separadas por espaços claros. Esta célula, à medida que amadurece, sofre degeneração mucóide, aparecendo em seu citoplasma vacúolos que aumentam progressivamente de número e tamanho, permanecendo separados por fino retículo de citoplasma. Nos estadios adiantados todo o protoplasma é substituído por um grande vacúolo. Durante esta evolução a célula aumenta de volume; o núcleo pode permanecer central, porém, na maioria das vêzes, é deslocado para a periferia, 
tornando-se achatado, pequeno, hipercromático, com nucléolo não visível. Colorações especificas (muci-carmim, tricrômico de Masson, van Gieson, Mallory) demonstram que os vacúolos são constituídos por substância de caráter mucoso.

Outro caráter microscópico importante do cordoma típico é o arranjo alveolar do parênquima, distinguindo-se alvéolos pequenos e grandes. Os pequenos são formados por acúmulos de células jovens, dando nítido caráter epitelial à neoplasia. Nos alvéolos grandes os elementos celulares apresentám-se em diferentes estadios de maturação, dispondo-se de maneira regularmente ordenada: na periferia situam-se células jovens, de pequenas dimensões; mais internamente aparecem as células fisaliforas, fortemente vacuolizadas e com pouca substância intersticial, dando ao conjunto o aspecto de tecido gorduroso; em zonas mais internas as células apresentam arranjo cordonal ou trabecular e estão contidas em uma substância mucóide intersticial abundante; na zona central do alvéolo as células perdem sua individualidade, transformando-se em verdadeiros sincicios contidos em um lençol mucoso. A maturação celular se dá da periferia para o centro, representando as zonas centrais dos alvéolos o tecido mais diferenciado.

Outros caracteres microscópicos acessórios dos cordomas são representados pelo depósito de glicogênio intracelular, vacuolização nuclear, mitoses raras e presença de células gigantes; no tecido intersticial encontram-se áreas de calcificação ou ossificação e, mais raramente, gôtas de glicogênio, gordura e vacúolos.

O Estroma dos cordomas é constituido por septos trabeculares largos, formados por tecido colágeno denso, que partem da cápsula e penetram até a profundidade do parênquima tumoral, dividindo-o em lóbulos Dos septos partem trabéculas que dividem os lóbulos em alvéolos, e destas, por sua vez, originam-se fibrilas reticulares que envolvem as células individualmente. Limitados às trabéculas mais finas existem vasos sangüineos de pequeno calibre rodeados por manguitos linfocitários; as áreas hemorrágicas, assinaladas no quadro macroscópico, podem limitar-se ao estroma ou, quando maiores, acometer também o parênquima.

O diagnóstico histológico dos cordomas nem sempre é feito com facilidade, principalmente quando são examinados pequenos fragmentos do tumor obtidos por biopsia ${ }^{16}$. A grande variedade do aspecto histológico, não só em casos diferentes mas também em áreas diversas de um mesmo tumor, pode conduzir a diagnósticos errôneos.

Metástases - Os cordomas têm grande tendência a invadir os vasos sangüín€os, formando verdadeiros trombos neoplásicos. Mabrey ${ }^{11}$ encontrou estas trcmboses em 6 casos, 5 dos quais ainda não tinham metástases. A via linfática é a mais importante, sendo comuns as metástases ganglionares; são descritas também metástases no fígado, pulmão, miocárdio, baço, rim, tireóide, pele e tecido celular subcutâneo e peritônio. Fato interessante é a grande freqüência de metástases nos cordomas sacrococcígeos $(62,5 \%$ segundo Mabrey ${ }^{11}$ ) e a raridade das mesmas nos cordomas intracranianos e vertebrais, havendo, até o presente, apenas 9 casos registrados?. 
Tratamento - A remoção cirúrgica dos cordomas é impossível, a não ser, e ainda assim excepcionalmente, daqueles localizados na região sacrococcigea onde podem ser realizadas operações radicais, com a retirada de todo o osso comprometido e das partes moles adjacentes. O caráter invasivo da neoplasia, que se propaga através das estruturas ósseas a grandes distâncias, torna inútil qualquer tentativa de excisão total dos cordomas vertebrais e intracranianos. A maioria dos autores recomenda remoções parciais do tumor para descomprimir estruturas vitais e operações de derivação do trânsito liquórico nos casos em que há bloqueios. A radioterapia em altas doses, empregada por alguns como complemento à cirurgia ou nos casos inoperáveis, é considerada por outros autores como de efeito meramente paliativo, não impedindo a evolução da neoplasia 5, 15, 16. Há trabalhos isolados com o uso de drogas quimioterápicas ${ }^{13}$ e introdução de substâncias radioativas no seio da massa tumoral através de intervençōes estereotáxicas ${ }^{21}$, parecendo tratar-se também, como a radioterapia, de recursos paliativos.

Prognóstico - A recidiva dos cordomas é a regra. Nos intracranianos o tempo de sobrevida após o início da sintomatologia é de 28 meses em média, segundo Mabrey ${ }^{11}$; com tratamento cirúrgico seguido de radioterapia, Kamrin e col. ${ }^{9}$ referem sobrevida média de 43 meses após a cirurgia. Os cordomas vertebrais e sacrococcígeos permitem sobrevivência maior, principalmente êstes últimos, em virtude de suas relações com estruturas de menor importância vital, chegando a atingir enormes dimensões sem comprometer sèriamente o estado geral do paciente. A presença freqüente de metástases nos cordomas sacrococcígeos torna o prognóstico bastante reservado nestas localizações.

\section{CASUISTICA}

Nosso material é constituído por 3 casos de cordomas, sendo um cervical e dois intracranianos, coletados entre 800 tumores afetando o sistema nervoso, operados na Clínica Neurológica da Faculdade de Medicina da Universidade de São Paulo, de janeiro de 1945 a setembro de 1964.

CASo 1 - GPF, 6 anos de idade, sexo feminino, côr branca. Registro H.C. 707181. Internada em 25-9-63. Doença iniciada há 3 anos, caracterizada por dores difusas no membro superior direito e déficit motor no hemicorpo direito com evoluçāo lentamente progressiva. Desde o inicio do quadro a paciente queixava-se de dores no pescoço que dificultavam a movimentação da cabeça. Exame clínico-neurológico Bom estado geral; desenvolvimento somático compativel com a idade; coluna vertebral sem desvios patológicos; dor local à compressão das últimas vértebras cervicais; dor à movimentação passiva e ativa da nuca; déficit motor nos membros direitos que se apresentam hipotróficos em relação aos contralaterais; reflexos profundos com respostas vivas nos membros superiores e no membro inferior esquerdo e exaltados no membro inferior direito; clono do pé direito; sinal de Babinski à direita; hipoestesia superficial no hemicorpo esquerdo poupando a face; hipoestesia profunda em ambos os membros inferiores, mais nitida à direita. Exames complementares - Radiografia da coluna cervical: alargamento do canal raqueano e erosão dos pedículos de $\mathrm{C}_{1}$ a $\mathrm{C}_{7}$. Liquido cefalorraqueano: punção entre $\mathrm{L}_{5}-\mathrm{S}_{1}$; aspecto límpido e xantocrômico; 55 leucócitos por $\mathrm{mm}^{3}(90,5 \%$ de linfócitos, $8 \%$ de monó- 
citos, $1 \%$ de plasmócitos e $0,5 \%$ de eosinófilos); $3.600 \mathrm{mg}$ de proteínas por $100 \mathrm{ml}$ (VDRL); não foram feitas as provas manométricas de Stookey pela falta de cooperação da paciente. Perimielografia (injeção de lipiodol por via lombar): parada total e duradoura do contraste ao nível de $\mathrm{C}_{6}$; os limites da coluna opaca são irregulares e sugerem processo expansivo intradural e extramedular.

Intervenção cirúrgica - Foi feita laminectomia de $\mathrm{C}_{1}$ a $\mathrm{C}_{7}$, sendo encontrado um tumor intradural comprimindo a medula que estava reduzida a delgada fita. A neoplasia situava-se na face ântero-lateral direita do canal raqueano e não apresentava aderências com a dura-mater ou com o tecido nervoso, sendo fàcilmente extirpada como um todo; havia um prolongamento do tumor que penetrava no buraco de conjugação entre $\mathrm{C}_{5}$ e $\mathrm{C}_{6}$, alargando-o consideràvelmente. A neoplasia era envolvida por cápsula espessa, com superfície bastante irregular; internamente era constituída por substância gelatinosa de côr pardacenta.
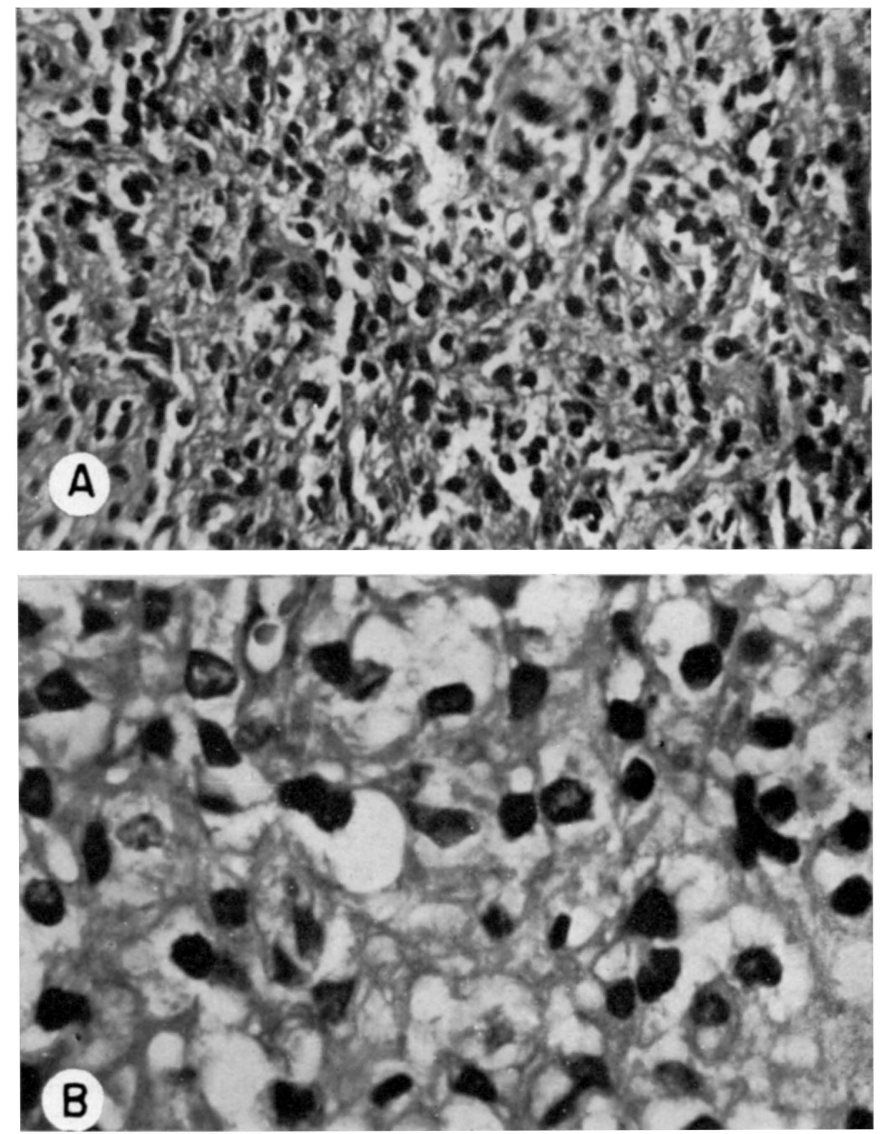

Fig. 1 -Caso 1 (GPF). Aspectos microscópicos da neoplasia: em $A$, acentuada celularidade que dá ao tumor aspecto sarcomatoso $(\mathrm{HE} 400 \times)$; em $B$, são evidentes as atipias nucleares $e$ a intensa vacuolização citoplasmática (H.E. $800 \times$ ). 
Exame histopatológico - Tumor constituido por células de pequeno volume, agrupadas e separadas entre si por escassa matriz acidófila homogênea e por fina rêđe capilar. As células são ovóides, com núcleos centrais, vesiculares, ligeiramente variáveis em tamanho e sem hipercromatismo. Atividade mitótica rara. $\mathrm{O}$ citoplasma das células mostra, ora amplo vacúolo único, ora múltiplos vacúolos dispostos de maneira radiada em redor dos núcleos. Existem áreas focais de calcificação. Diagnóstico: cordoma (fig. 1).

O caso teve boa evolução após o ato cirúrgico com recuperação total dos déficits motor e sensitivo. Em revisão feita em maio de 1964 não foi assinalado qualquer sintoma neurológico.

CASo 2 - VM, 17 anos de idade, sexo feminino, côr branca. Registro H.C. 332369. Internada em 3-11-53. Moléstia iniciada há 2 anos com estrabismo convergente, que melhorou com o uso de óculos; ao mesmo tempo começou a sentir vertigens e ruídos no ouvido direito, com queda progressiva da acuidade auditiva dêsse lado; um ano após surgiram cefaléia, náuseas, vômitos e desvio progressivo da rima oral para a esquerda. Nos últimos meses vinha sentindo dores na regiāo cervical. Exame clinico-neurológico — Bom estado geral; sem rigidez da nuca; coluna vertebral sem desvios patológicos e não dolorosa à palpação; discreta anisocoria com pupila direita maior que a esquerda; reflexos fotomotores normais; hipoestesia no território do $5^{\circ}$ nervo, paralisia facial de tipo periférico, hiporreflexia vestibular e hipoacusia mista à direita; fundos oculares normais. Exames complementares - Craniograma: abobada de espessura regular, sem alterações estruturais apreciáveis; sela turca de diâmetros bastante amplos, com destruição dos processos clinóides anteriores e posteriores; destruição parcial da pirâmide direita; calcificações suprasselares. Líquido cefalorraqueano normal. Carotidoangiografia direita: deslocamento do sifão carotídeo para cima e para a frente; artéria cerebral média desviada para cima, descrevendo trajeto curvilíneo de concavidade inferior; não há desvios transversais das artérias cerebrais. Iodoventriculografia: acentuada elevação da porção infundibular e do soalho do $3^{\circ}$ ventrículo; acentuado deslocamento para trás e para cima do aqueduto cerebral e do 4 s ventrículo; moderado desvio destas estruturas para a esquerda (fig. 2).

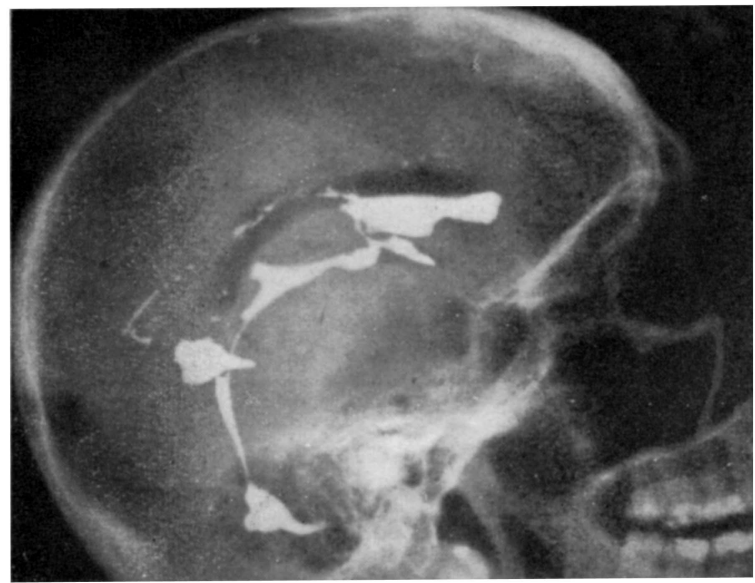

Fig. 2 - Caso 2 (MV). Iodoventriculografia mostrando acentuada elevacão $e$ deslocamento posterior do $3^{\circ} e 4^{\circ}$ ventrículos $e$ do aqueduto de Sylvius.

Intervenção cirúrgica - Foi feita hemicraniectomia direita da fossa posterior (tipo Dandy), encontrando-se um tumor encapsulado no ângulo ponto-cerebelar; aberta a cápsula verificou-se ser a neoplasia constituida por tecido gelatinoso, em meio ao qual havia grande quantidade de fragmentos calcificados. Tôda a porção 
do tumor localizada na fossa posterior foi esvaziada, tendo sido deixada a cápsula no local em virtude das firmes aderências com o tronco encefálico. Não foi possivel verificar continuidade da neoplasia para a fossa média.

Após o ato cirúrgico a paciente não recuperou a consciência, permanecendo em coma profundo e com graves distúrbios neurovegetativos, vindo a falecer 36 horas depois.

Necropsia (SS-38.182). Encéfalo - Macroscopia: Em correspondência com a sela turca e clivo de Blumenbach foi encontrada uma formação globosa, fortemente aderida aos planos ósseos, medindo cêrca de $5 \mathrm{~cm}$ de diâmetro e estendendo-se lateralmente sôbre as pirâmides temporais, especialmente no lado direito. Esta formação era revestida pela dura-mater e sôbre ela estavam distendidos os nervos oculomotores. A hipófise estava deslocada rostralmente. A face do tumor que fazia saliência na hemifossa cerebelar direita não tinha revestimento dural e apresentava áreas de hemorragia na superficie. Aos cortes, o tecido neoplásico apresentava-se brilhante, opaco, finamente granuloso, com extensas áreas de hemorragia; de espaço a espaço encontram-se iinas esquirulas de consistência óssea (fig. 3 ).

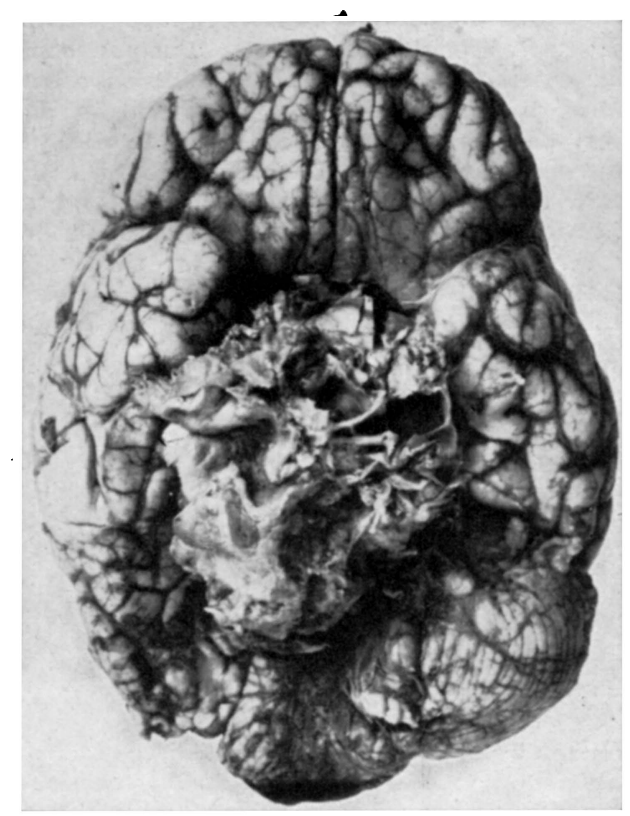

Fig. 3 - Caso 2 (VM). Aspecto macroscópico da neoplasia.

Microscopia: Examinada através da lupa a neoplasia assemelha-se, grosseiramente, a tecido adiposo. Analisada com aumentos maiores observa-se que aquêle aspecto é determinado pela vacuolização intensa das células em tôda a extensão do corte. Assim, o citoplasma é representado por uma fina rima periférica eosinófila, apresentando-se o núcleo relativamente pequeno, tendendo ao ovóide, e com cromatina distribuida sob a forma de pequenos grânulos. A maioria das células é poliédrica e com limites precisos, variando bastante de tamanho. Em algumas áreas as células apresentam-se com os limites pouco nitidos, estando seu material protoplasmático fundido sob forma de massas irregulares, amorfas, de tonalidade rósea. 
Pequenos vasos sangüíneos, acompanhados de finas faixas conjuntivas, representam o estroma da neoplasia. Chamam a atenção a presença de lamelas de tecido ósseo no seio da neoplasia, bem como áreas de hemorragia (fig. 4).

Não foram examinados os demais órgãos (necropsia parcial).
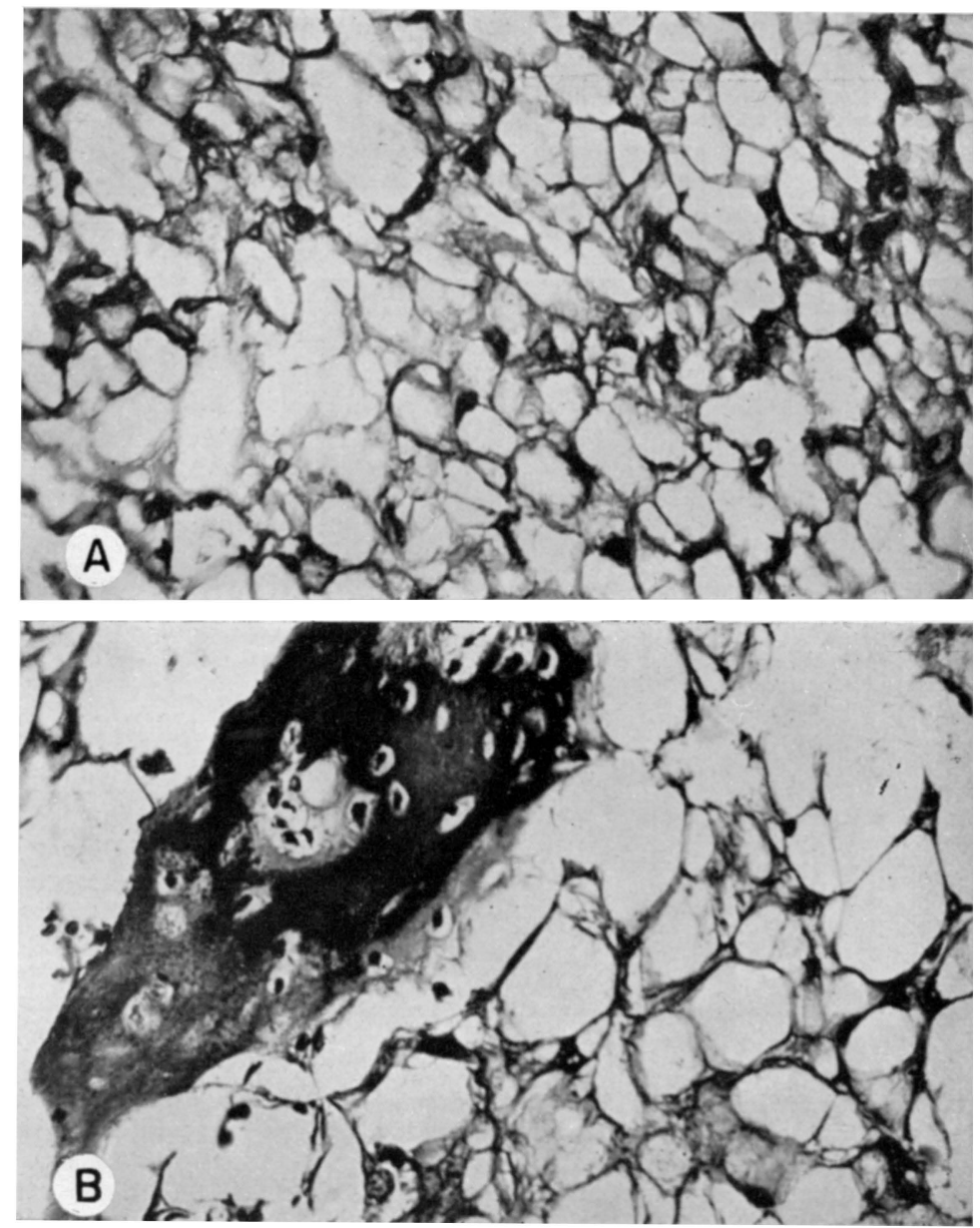

Fig. 4 C Caso 2 (VM). Aspectos microscópicos da neoplasia: em A, células intensamente vacuolizadas com os núcleos recalcados para a periferia, dando ao corte o aspecto de tecido gorduroso (H.E. $400 \times$ ); em $B$, vê-se um fragmento ósseo neoformado e cavidades resultantes da rotura das membranas celulares (H.E. $800 \times$ ).

Caso 3 - GRG, 23 anos de idade, sexo masculino, côr branca. Registro H.C. 724462. Internado em 24-4-64. Inicio da moléstia há 4 meses com crise convulsiva generalizada seguida de coma; desde então, hemiplegia direita e afasia que regrediram parcialmente, dificuldade à marcha com tendência à queda para a direita, cefaléia, vômitos e diminuição progressiva da acuidade visual. Exame clinico-neu- 
rológico - Paciente em bom estado geral; confuso, desorientado alopsìquicamente, pueril e eufórico; palavra disártrica, assemelhando-se à escandida; marcha titubeante agravada pela amaurose; discreto déficit motor nos membros do hemicorpo direito; reflexos profundos simétricos e com resposta normal; clono esgotável no pé direito; discreta dismetria no membro superior esquerdo; amaurose bilateral; midriase bilateral, com reflexos fotomotores ausentes; paresia facial esquerda do tipo periférico; edema das papilas opticas. Exames complementares - Craniograma: lesōes osteolíticas extensas da sela turca e do plano esfenoidal; calcificaçōes projetando-se junto às clinóides posteriores (fig. 5). Exame otorrinolaringológico: não foram evidenciados abaulamentos no rinofaringe. Eletrencefalograma normal. Carotidoangiografia bilateral: sinais de discreta dilatação ventricular. Iodoventriculografia: dilatação e elevação do $3^{\circ}$ ventrículo; aqueduto cerebral e $4^{\circ}$ ventrículo desviados para trás e para a direita.

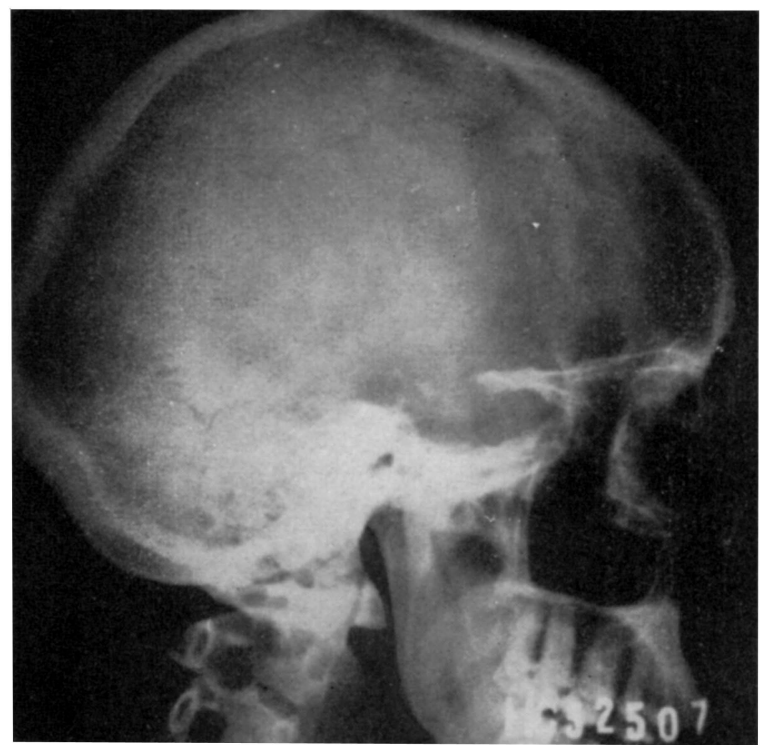

Fig. 5 - Caso 3 (GRG). Craniograma mostrando extensas destruições ósseas da sela turca e do plano esfenoidal, assim como calcificações suprasselares.

Intervenção cirúrgica - Foi feita craniotomia frontal esquerda para a abertura da lâmina terminal e biopsia do tumor; os nervos ópticos estavam muito estirados e o quiasma elevado por massa tumoral que se projetava através da sua fúrcula anterior. Com dificuldade conseguiu-se realizar a abertura da lâmina terminal; pela abertura da parede anterior do $3^{\circ}$ ventrículo notava-se abaulamento acentuado do soalho do mesmo. Foi retirada pequena quantidade de material para biopsia que revelou tratar-se de carcinoma sólido de origem indeterminada.

Após o ato cirúrgico o paciente não recuperou a consciência, evoluindo com hipertermia acentuada e rebelde à terapêutica e com tendência à hipotensão arterial. No $10^{\circ}$ dia depois da intervenção teve pequena hematêmese, falecendo logo a seguir.

Necropsia (SS-68.897) - O exame macroscópico mostrou estar a fossa média esquerda da base do crânio ocupada por neoplasia de $5 \times 6 \mathrm{~cm}$, bastante friável, de côr acinzentada e contornos irregulares, que incluía o corpo do esfenóide, a adeno e neuro-hipófise. Em secção sagital mediana do encéfalo verifica-se que a massa neoplásica invade a fossa interpeduncular, infiltrando bilateralmente a porçāo ba- 
silar do têrço superior da ponte e a região mesencefálica adjacente, acometendo tanto os pedúnculos cerebrais como o tegmento mesencefálico; as seccooes da neoplasia mostraram áreas de hemorragia e necrose. O tumor provocava acentuado abaulamento do assoalho do $3^{\circ}$ ventriculo e obstruía o aqueduto de Sylvius. Os vasos do circulo arterial do encéfalo estão envolvidos pela neoplasia, sem sinais de compressão (fig. 6). Microscopia — Neoplasia constituida por massas celulares de
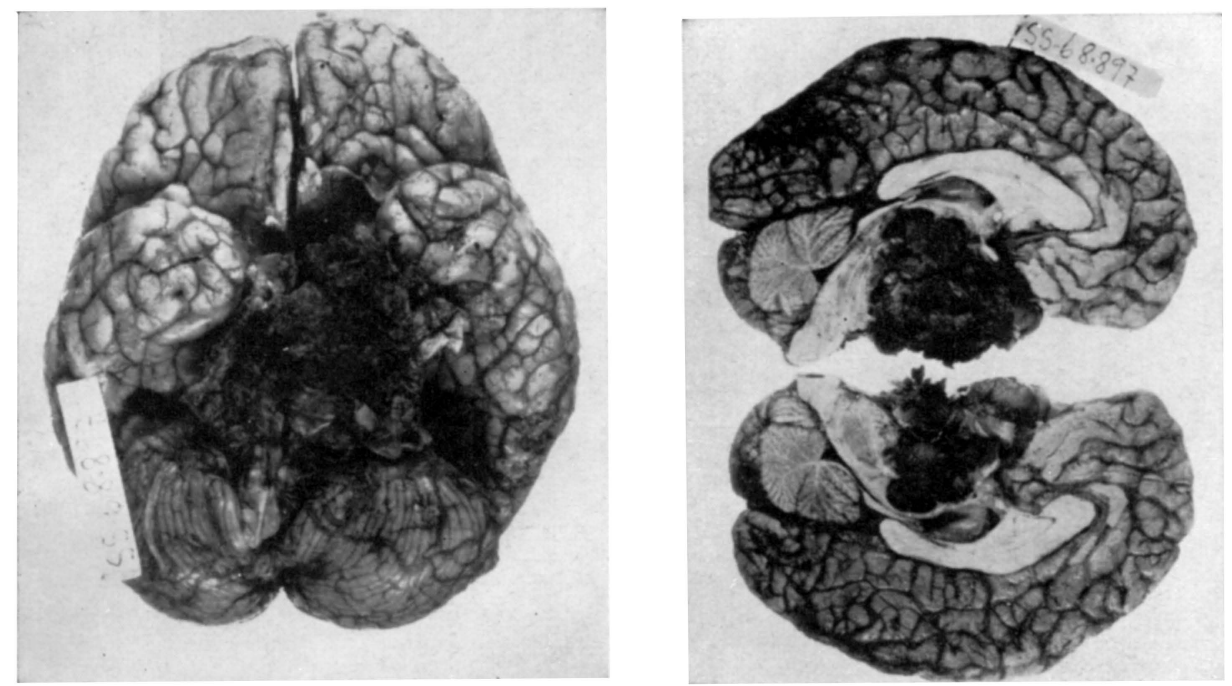

Fig. 6 - Caso 3 (GRG). Aspectos macroscópicos da neoplasia.

tamanho variado, envolvidas por finas traves conjuntivas. As células têm forma poligonal ou arredondada e núcleos ovóides, não tendo limites precisos entre si; o citoplasma é acidófilo e finamente rendilhado, em virtude da presença de vacúolos; outras vêzes existe um vacúolo único, sendo o núcleo deslocado para a periferia, conferindo ao conjunto o aspecto de tecido gorduroso. Em outras áreas as células têm arranjo folicular, limitando espaços em cujo interior existe uma substância homogênea, acidófila, um pouco mais clara que o citoplasma. Existem áreas de hemorragia e numerosos focos de ossificação. Não foram observadas mitoses. Diagnóstico: Cordoma (fig. 7).

\section{COMENTARIOS}

A raridade dos cordomas entre os tumores que comprometem o sistema nervoso fica, mais uma vez, confirmada pela baixa incidência destas neoplasias em nosso material $(3,7 \%)$.

Nos três casos, o início da sintomatologia ocorreu precocemente, principalmente no caso 1 em que o quadro clínico se iniciou aos 3 anos de idade, fato êste bastante raro. Nos casos 1 e 2 a evolução dos sintomas foi lenta ( 3 e 2 anos, respectivamente), como refere a maioria dos autores, porém no caso 3 houve início abrupto da sintomatologia, possìvelmente em conseqüência de hemorragia intratumoral ${ }^{16}$. Em nenhum dos casos havia referências a traumatismos antecedendo à eclosão da sintomatologia. 

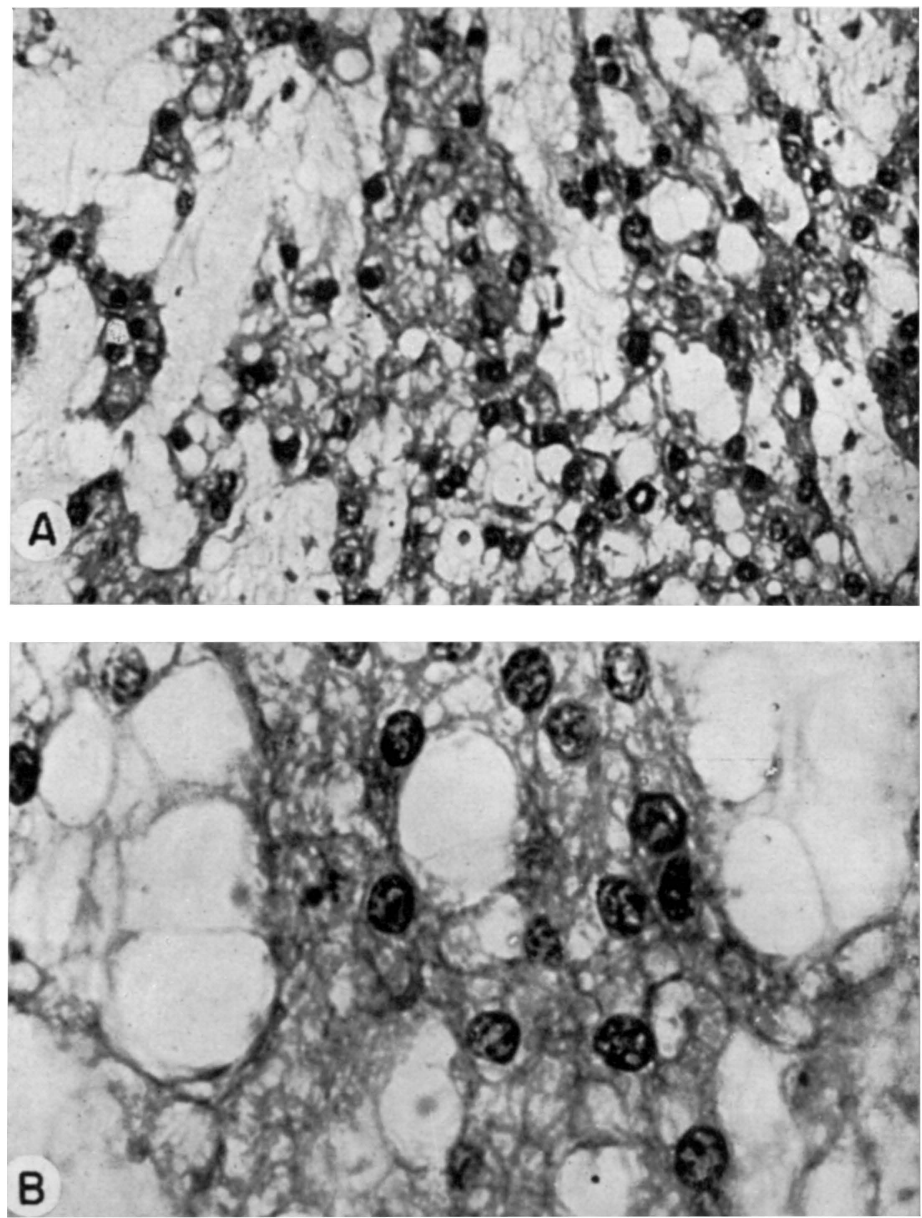

Fig. 7 - Caso 3 (GRG). Aspectos microscópicos da neoplasia: em $A$, arranjo cordonal do tumor e grandes cavidades entre grupos celulares (H.E. $400 \times)$; em $B$, aspecto característico da célula fisalifora com seu citoplasma finamente rendilhado, semelhante a bôlhas de sabão (H.E. $800 \times$ ).

A dificuldade para o diagnóstico dos cordomas em virtude da falta de dados específicos, também se fêz notar em nossas observações, sendo que em nenhum caso foi feito o diagnóstico correto antes da intervenção cirúrgica: no caso 1 não foi aventada qualquer hipótese quanto à natureza do tumor; no caso 2 foram feitas as hipóteses de colesteatoma ou sarcoma osteogênico e, no caso 3 , de craniofaringeoma.

O caso 1 apresentou quadro de processo compressivo radículo-medular de evolução lenta, caracterizando-se clinicamente uma síndrome de Brown- 
Sequard (hemissecção medular); radiolòlogicamente havia discreta destruição óssea. No ato cirúrgico foi encontrado um tumor intradural de pequenas dimensões, fàcilmente enucleável, que não apresentava caráter invasivo. Estas características são mais encontráveis nas ecordoses fisalíforas do que nos cordomas, apesar dêstes coristomas não darem, em geral, sintomatologia.

No caso 2 houve acometimento de vários nervos cranianos $\left(3 .^{\circ}, 5 .^{\circ}, 7 .^{\circ}\right.$ e $8^{\circ}$ ) sem comprometimento de vias motoras, sensitivas ou cerebelares, apesar das grandes dimensões da neoplasia; no caso 3 , ao contrário, predominavam os sintomas decorrentes da lesão de vias motoras e cerebelares, havendo comprometimento sòmente do nervo facial.

Nos casos 2 e 3 o exame radiológico mostrou extensas destruições ósseas e calcificações intratumorais, que representam importantes elementos para a suspeita de cordomas; no caso 1 não foram evidenciadas lesōes ósseas de vulto. Os exames radiológicos contrastados contribuíram para a localização exata das neoplasias, não fornecendo elementos para o diagnóstico da sua natureza.

O exame do líquido cefalorraqueano, feito nos casos 1 e 2, mostrou no primeiro, um quadro de bloqueio total do canal raqueano, tendo resultado normal no caso 2.

No caso 3 foi feita biopsia que sugeriu tratar-se de carcinoma sólido indiferenciado. Poppen ${ }^{16}$ chama a atenção para a dificuldade diagnóstica dos cordomas quando são examinados fragmentos pequenos da neoplasia, em virtude da possibilidade de existirem áreas com estrutura totalmente atípica ao lado de outras com as caracteristicas próprias do cordoma.

Do ponto de vista anátomo-patológico, os casos 2 e 3 apresentaram-se como cordomas típicos; no caso 1 , ao lado de áreas com o quadro histológico característico da neoplasia cordal, existiam outras com aspecto totalmente anaplásico, lembrando um tumor sarcomatoso.

\section{RESUMO}

Após sumária revisão da literatura sôbre os cordomas, são discutidos a origem e localização, incidência, sintomatologia, aspectos radiológicos e labcratoriais, os dados anátomo-patológicos, o problema das metástases, o tratamento e o prognóstico.

São apresentados 3 casos de cordomas (dois intracranianos e um cervical) encontrados entre 800 casos de neoplasias afetando o sistema nervoso, operados na Clínica Neurológica da Faculdade de Medicina da Universidade de São Paulo. São feitos comentários sôbre alguns aspectos interessantes, entre os quais: a incidência muito precoce no caso 1, o início abrupto da sintomatologia no caso 3 , o êrro do diagnóstico histopatológico do material de biopsia no caso 3 , e o aspecto histológico atípico (sarcomatoso) no caso 1 . 


\section{SUMMARY \\ Congenital tumors of the nervous system: chordomata.}

After a brief survey of the literature on chordomata, its origin and localization, incidence, symptoms, radiological and laboratorial aspects, pathclogical anatomy, the problem of metastasis, treatments and prognosis are discussed.

Three cases (two being intracranial and one cervical) among 800 neoplasms of the nervous system operated at the Neurological Department of University of São Paulo Medical School are reported. Some interesting aspects are discussed: the very early onset in the case 1 , the sudden start of symptomatology in case 3, the error of histological diagnosis of the biopsy material in case 3 and the atypical (sarcomatous) histological aspects in case 1 .

\section{REFERENCIAS}

1. BAKER, H. W. \& COLEY, B. L. - Chordoma of lumbar vertebra. J. Bone and Joint Surg., 35A:403-408, 1953. 2. CANELAS, H. M. \& JULIAO, O. F. - Paralisias múltiplas de nervos encefálicos produzidas por neoplasias da base do crânio Arq. Neuro-Psiquiat. (São Paulo), 19:185-219, 1961. 3. CONGDON, C. C. - Proliferative lesions resembling chordoma following puncture of the nucleus pulposus in rabbits. J. Nat. Cancer Inst., 12:893-907, 1952. 4. CONGDON, C. C. - Benign and malignant chordomata. Clinic-anatomical stud'y of 22 cases. Am. J. Path., 28:793821, 1952. 5. FORTI, E. \& VENTURINI, G. - Contributo alla conoscenza delle neoplasie notocordali. Riv. Anat. Pat. Oncol., 17:317-396, 1960. 6. GIVNER, I. - Oph-thalmologic features of intracranial chordoma and allied tumors of the clivus. Arch. Ophthal., 33:397-403, 1945. 7. GODTFREDSEN, E. - Eye and nerve symptoms in connection with cranial chordoma. Acta Ophthal. Kbh., 21:224-236, 1943. 8. JAFFE, H. L. - Tumors and Tumorous Conditions of the Bones and Joints. Lea \& Febiger, Philadelphia, 1959. pp. 451-462. 9. KAMRIN, R. P.; POTANOS, J. N. \& LAWRENCE POOL, J. - An evaluation of the diagnosis and treatment of chordoma. J. Neurol. Neurosurg. a. Psychiat., 27:157-165, 1964. 10. KERNOHAN, J. W. \& SAYRE, G. P. - Chordoma. In Atlas of Tumor Pathology. Armed Forces Institute of Pathology, Washington, 1952, vol. 1, pp. 118-122. 11. MABREY, R. E. - Chordoma. A study of 150 cases. Am. J. Cancer, 25:501-517, 1935. 12. MAFFEI, W. E. - As Bases Anátomo-Patológicas da Neuriatria e da Psiquiatria. Imp. Metodista, São Paulo, 1951, vol. II, pp. 267-271. 13. MCSWEENEY, A. J. \& RICHARD SCHOLL, P. Metastatic chordoma. Use of Mechiorethamine (nitrogen mustard) in chordoma therapy. Arch. Surg., 79:164-167, 1959. 14. MIGNONE, C. \& ELEJALDE, G. - Cordomas. An. Fac. Med. Univ. São Paulo 16:409-441, 1940. 15. MOYA, G. - Les chordomes sphéno-occipitaux. Révision critique à propos de deux cas nouveaux. Encéphale 49:495-543, 1960. 16. POPPEN, J. L. \& KING, A. B. - Chordoma: experience with thirteen cases. J. Neurosurg., 9:139-163, 1952. 17. RIBBERT, H. Ueber die experimentelle Erzengung einer Ecchondrosis physalifora. Verhandl. d. Kong. f. inn. Med., 13:455-464, 1895. Cit. por Congdon ${ }^{3}$ e por Russell e Rubinstein ${ }^{18}$. 18. RUSSELL, D. \& RUBINSTEIN, L. J. - Pathology of Tumours of the Nervous System. Edward Arnold, Londres, 1959, p. 214. 19. SWEET, W. H. - A review of dermoid, teratoid and teratomatous intracranial tumors. Dis. Nerv. Syst., 1:228-238, 1940. 20. ZERBINI, E. J. - Estudo clinico dos cordomas sacrococcigianos. Rev. Cirurg. de São Paulo 5:355-394, 1940. 21. ZOLTAN, L. \& FENYES, I. - Stereotactic diagnosis and radioactive treatment in a case of spheno-occipital chordoma. J. Neurosurg., 17:888-900, 1960.

Clinica Neurológica -- Hospital das Clínicas da Faculdade de Medicina da Universidade de São Paulo - Caixa Postal 3461 - São Paulo, Brasil. 